\title{
ANTI-ATHEROSCLEROTIC EFFECTS OF OATS (AVENA SATIVA) ON BLOOD VESSELS OF ALBINO RATS' TONGUE
}

\author{
Sally H Abo Baker* and Amira A. R. Moawad*
}

\begin{abstract}
Objective: To investigate anti-atherosclerotic effect of oats against increased fat diet which result in atherosclerosis in albino rats.

Methodology: 30 adult male albino rats divided into three groups, 10 rats each: group I: negative control take basal diet, group II take diet with increased cholesterol level for 8 weeks, group III fed on diet with increased cholesterol level for 60 days then given oats-supplemented diet $(20 \% \mathrm{~b} / \mathrm{w})$ besides the same diet of cholesterol for another 4 weeks. The animals were euthanized under mild ether anesthesia at the end of 8th week for group II and at the end of 12th week for group III. and the blood was taken from inner canthus of the eye, total serum cholesterol level has been observed and each animal has cholesterol level more than $250 \mathrm{mg} / \mathrm{dl}$ was estimated to be hyperlipidemic rat. Rats' tongue carefully dissected out and processed for Haematoxylin \& Eosin and alpha smooth muscle actin staining.
\end{abstract}

Results: histological examination revealed that atherosclerosis would lead to endothelial damage of the blood vessels of the tongue; rats received oats in their diet showed regeneration of the endothelial cells. Immuno-histochemical study showed increase positive immunoreactivity in blood vessels of tongue of group II rats that received high fat diet compared with rats of negative control group or rats of oat group

Conclusion: including oats in diet can be effective in reducing serum cholesterol.

KEYWORDS: Atherosclerosis, Oats, Alpha smooth muscle actin

\section{INTRODUCTION}

Atherosclerosis is an arterial wall oxidative disease manifested as elevation of (LDL) in blood ${ }^{(1)}$. Hyperlipidemia is one of major atherosclerosis - related factors, others being, diabetes mellitus, hypertension, smoking and other factors ${ }^{(2)}$.
Atherosclerosis is characterized by vascular areas containing mononuclear and smooth muscle cells proliferation causing the arterial wall to harden and thicken ${ }^{(3)}$.

Atherosclerosis begins with endothelium damage, resulting in dysfunction of the vasodilated

* Lecturer of Oral Biology Department, Faculty of Dentistry, Mansoura University, Egypt 
endothelial cells. Therefore, endothelium cannot withstand growth, hemostasis or tone, resulting in inflammation through circulatory system ${ }^{(4)}$.

Atherosclerosis leads to Blood stagnation, which is a major pattern of retardation in circulation. The major symptoms may include tenderness, darkpurple lips and fingernails, stabbing pain with a fixed position, lumps, local purpura, a blue-violet tongue with engorged sublingual collateral vessels, and an intermittent pulse. ${ }^{(5)}$

Many blood vessels and nerves nourish the tongue. It takes blood supply from lingual artery, external carotid artery, tonsillar branch of the facial artery, ascending pharyngeal artery. The lingual veins, drain into the internal jugular vein ${ }^{(6)}$.

Plants have many important functions in preserving human health and act as valuable medicines ${ }^{(7)}$. Oat (Avena sativa) is a seed - grown cereal grain specie. Oats are not only suitable for human consumption as rolled oats and oat meal, but it can also be used as livestock feed. Oats are enriched food with nutrients associated with low blood cholesterol when regularly consumed ${ }^{(8)}$.

Oats are of high dietary value compared to other Gramineae cereals since it contains; selenium, tryptophan, thiamine, vitamin $\mathrm{E}$ and manganese. It contains more protein content than any other grains of cereals ${ }^{(9)}$ with avenin protein ${ }^{(10)}$. Oat bran contains beta-glucan, which is a highly viscous soluble polysaccharide ${ }^{(9)}$. Benefits of oats could be seen in alleviation of; depression, rheumatism, chronic neurological pain, bladder atonia, and skin cleanser, emollient from outside ${ }^{(9)}$.

It can also help to reduce blood sugar levels, ${ }^{(11)}$ reduce constipation in older people, ${ }^{(12)}$ decrease blood pressure levels, ${ }^{(13)}$ and play a role coronary heart disease reduction ${ }^{(14)}$.
( $\alpha$-SMA) is found predominantly in smooth muscle cells of blood vessels and have a major role in collagen fiber formation, recently in the absence of tissue injury, alpha-SMA was found in mouse subcutaneous tissue fibroblasts ${ }^{(15)}$. Migration and proliferation of Smooth muscle cell besides inflammation that occur in cells are complex biological processes, which produce clinical manifestations of atherogenesis and atherosclerosis ${ }^{(16)}$.

\section{Methodology:}

Rats: 30 albino rats, with average weight of $150 \mathrm{gm}$ used in this study. Animals were kept in plastic cages and were fed and provided with water. Healthy animals were randomized and maintained at $20 \pm 5 \mathrm{C}$.

Experimental protocol was approved by, Faculty of dentistry, University of Mansoura, Egypt.

Experimental design: animals divided equally into three groups:

Group I : (control group) rats were fed with commercial diet.

Group II: rats fed on diet that elevates cholesterol level for 8 weeks ${ }^{(17)}$.

Group III: rats fed on diet that elevates cholesterol level for 8 weeks then given oatssupplemented diet** $(20 \% \mathrm{~b} / \mathrm{w})$ besides the same diet of cholesterol for another 4 weeks ${ }^{(18)}$.

\section{Induction of atherosclerosis:}

The animals fed on atherogenic Diet for 8 weeks. Atherogenic diet consisting of $8 \mathrm{~g}$ of saturated fat, $2 \mathrm{~g}$ of cholesterol, and $100 \mathrm{mg}$ calcium were added to $90 \mathrm{~g}$ powdered commercial pellet diet and mixed thoroughly. The rats took high fat diet together with weekly vitamin-D3 (3, 20,000 IU) orally in $1.5 \mathrm{ml}$ of olive oil ${ }^{(19)}$. At the end of $8^{\text {th }}$ week, animals were euthanized and the blood was obtained from inner

** Oats have been obtained from Nahrain Company for food industries Cairo-Egypt, and have been prepared in powder form and given in the diet to the animals. 
canthus of eye, total serum cholesterol level has been observed and each animal has cholesterol level above $250 \mathrm{mg} / \mathrm{dl}$ was considered as rat with high cholesterol level ${ }^{(20)}$. Rats tongue were dissected out and processed for Haematoxylin \& Eosin and alpha smooth muscle actin staining.

\section{RESULTS:}

Gross observations: the body weight of the atherosclerotic rats (group II) were increased in relation to the control animals and animals that fed oats (table1)

\section{Haematoxylin \& Eosin results:}

Histological examination revealed the following (Fig A):

Group I: The dorsal surface of the tongue had no remarkable changes with normal architecture of the blood vessels with normal endothelial cells and flat nuclei.

Group II: There is a loss of the endothelial nuclei in most parts of the blood vessels with loss of normal architecture of the endothelial cells.

Group III: There is regeneration of normal architecture of the blood vessels with its endothelium and so do the pericytes around the blood vessels.

\section{Immuno-histochemical results (Fig B) and table 3}

Group I: showed positive reaction in the blood vessels.

Group II: showed increase positive immunoreactivity in the blood vessel.

Group III: showed moderate positive reaction in the blood vessels.

\section{Statistical results:}

Data were parametric and presented in mean and standard deviation. One way (ANOVA) and Tukey were used to compare quantitative parametric data. $P$ value below than 0.05 was considered to be statistically significant.

TABLE (1) Showing increased body weight in group II in relation to group I and group III

\begin{tabular}{|c|c|c|c|}
\hline & control & Athero & oats \\
\hline Initial & $158.75 \pm$ & $148.79 \pm$ & $150.31 \pm$ \\
weight & 7.92 & 15.91 & 11.97 \\
\hline Final & $167.62 \pm$ & 204.03 & $192.83 \pm$ \\
weight & 17.73 & \pm 9.67 as & 11.12 a' \\
\hline
\end{tabular}

Data expressed as mean $\pm S D$

SD: standard deviation P: Probability

Test used: One-way ANOVA followed by post-hoc Tukey a: significance vs. Control group $(P<0.05)$.

$b$ : significance vs. Athero Group $(P<0.05)$.

I: significance vs initial weight time $(P<0.05)$.

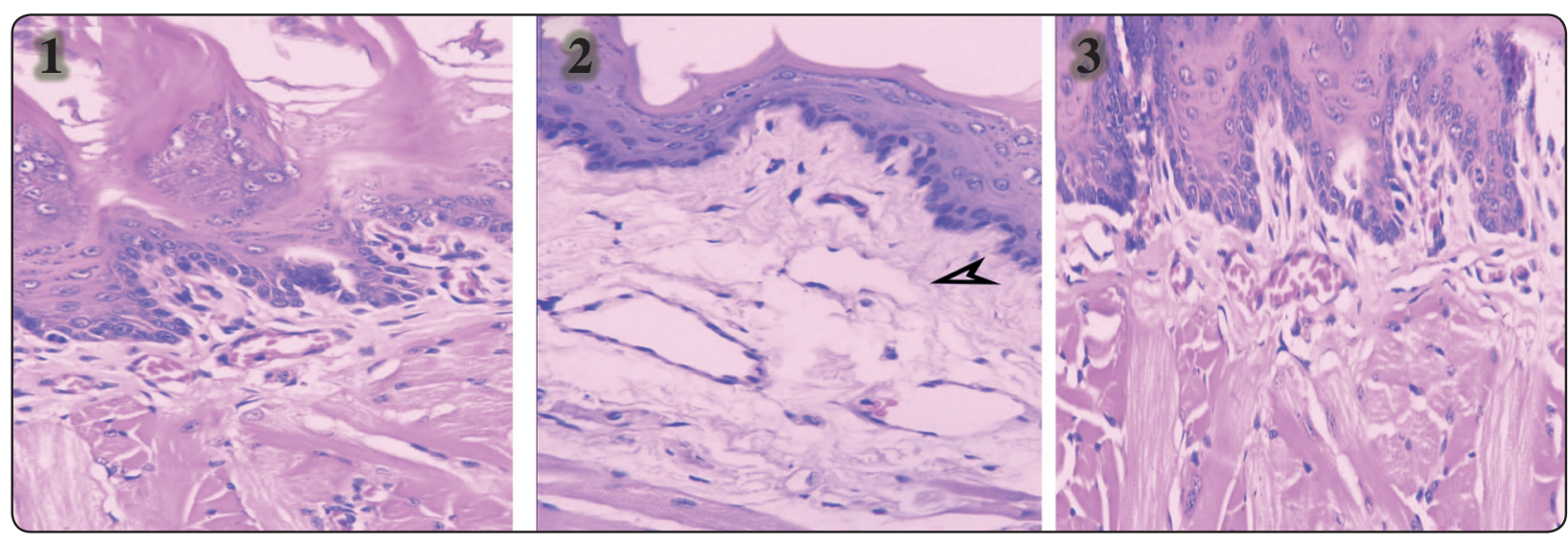

Fig (A) (1) group I showing normal architecture of the blood vessels with normal endothelial cells and flat nuclei, (2) group II showing loss of the normal architecture of endothelial cells with loss of their nuclei in most parts of the blood vessels (arrow head, (3) group III showing regeneration of normal architecture of the blood vessels with its endothelium (H\&E x 400) 


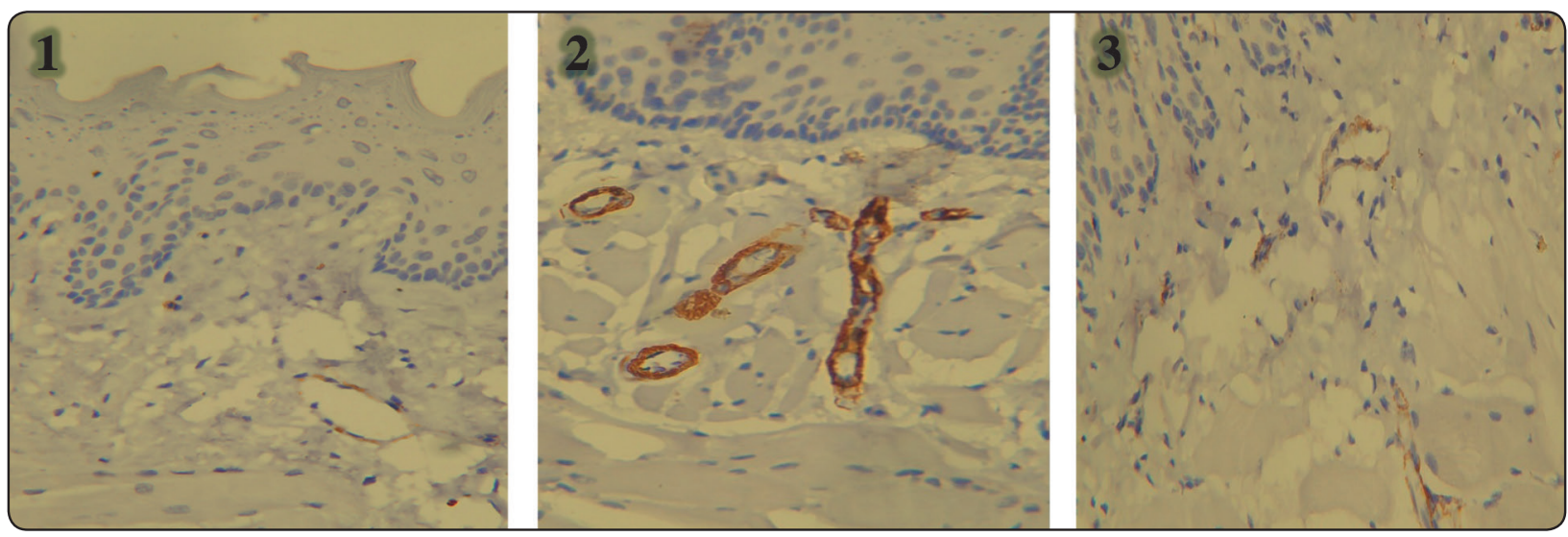

Fig B: (1) group I showing positive reaction in the blood vessels (2) group II showing increase positive immunoreactivity in the blood vessel, (3) group III showing moderate positive reaction in the blood vessels. (IHC x 400)

TABLE (2) Showing high cholesterol level in atherosclerotic group compared to negative control and oat group

\begin{tabular}{|c|c|c|c|}
\hline & control & Athero & oats \\
\hline Cholesterol & $140.21 \pm 6.35$ & $250.33 \pm 12.79^{\text {a }}$ & $\begin{array}{c}195.28 \pm 3.84 \\
\text { ab }\end{array}$ \\
\hline
\end{tabular}

Data expressed as mean $\pm S D$

SD: standard deviation

P: Probability

Test used: One-way ANOVA followed by post-hoc Tukey

a: significance vs. Control group $(P<0.05)$.

b: significance vs. Athero $\operatorname{Group}(P<0.05)$.

TABLE (3) Showing high immunoreactivity in atherosclerotic group compared to control and oat group

\begin{tabular}{|l|c|c|c|}
\hline & control & Athero & oats \\
\hline$\%$ Area & $0.49 \pm 0.098$ & $3.555 \pm 0.71^{\mathrm{a}}$ & $1.70 \pm 0.34^{\mathrm{ab}}$ \\
\hline
\end{tabular}

Data expressed as mean $\pm S D$

SD: standard deviation P: Probability

Test used: One-way ANOVA followed by post-hoc ukey

a: significance vs. Control group $(P<0.05)$.

b: significance vs. Athero Group $(P<0.05)$.

\section{DISCUSSION}

Atherosclerosis is a complicated disorder that affects large- and medium-sized muscular arteries; it is manifested as vascular inflammation, endothelial impairment, and accumulation of lipids, calcium, cholesterol and cellular debris within vessel wall's intima. All of this results in formation of plaque, obstruction of lumen, vascular remodeling, and blood flow impairement, and reduce the supply of oxygen to target organs ${ }^{(21)}$.

Oats are a whole-grain food with many health benefits including lower levels of blood sugar, lower risk of heart disease and weight loss ${ }^{(22)}$.

In the present study, the gross finding revealed marked increase in the body weight of atherosclerotic animals compared with negative control and oat animals, these results are in accordance with YanJun Jia et al, 2013; who found that the body weights in rats fed with High fat diet were significantly higher than in rats with normal pellets at day $28^{(23)}$.

Brochu et al., 2000 stated that; oats can help in maintenance of healthy weight. Fiber content of oat can help to maintain weight and prevent further increase in weight ${ }^{(24)}$.

The histological findings of the dorsal surface of tongue revealed normal architecture of the blood 
vessels with normal endothelial cells and flat nuclei in-group I compared with loss of the endothelial nuclei in most parts of the blood vessels with loss of normal arrangement of endothelial cells in group II. Group III showed regeneration of normal architecture of the blood vessels. These results in agreement with Irena Vukovic et al; 2006 who found that in late stages of atherosclerosis, there is morphological damage of the endothelium ${ }^{(25)}$. Also R. Ojeda et al; stated that it has been shown that appearance of endothelial damage and/ or dysfunction is the first step in atherosclerosis development ${ }^{(26)}$.

Our results were supported by Liu L et al; 2004 who stated that oats have an important role in decreasing the risk of atherosclerosis ${ }^{(27)}$, also Queenan KM et al; 2007 found that Oat fiber produces modest cholesterol levels reductions and can have a slight positive modification of coronary artery disease ${ }^{(28)}$.

Hematoxyline and eosin results of the present study were supported by alpha smooth muscle actin immune-histochemical analysis, which showed significant difference between all groups, Kisoo Pahk et al; 2017 found that normal artery consisted of (SM-MHC) and media positive $\alpha$-smooth muscle actin ( $\alpha$-SMA). There were many $\alpha$-SMA - positive cells in neo intima in atherosclerotic right carotid artery, while SM - MHC - positive cells, hardly seen ${ }^{(29)}$.

In agreement with our results Azuma K et al; 2009 observed that in 5-6 months old Apo lipoprotein-E deficient mice, appearance of ( $\alpha$-SMA) was significant in endothelial cells particularly in atheromatous plaques's luminal surface ${ }^{(30)}$.

Andersson KE et al; 2010 stated that Oats have antioxidant and anti-inflammatory components that affect atherogenesis ${ }^{(31)}$. Also Maisaa M. AL-Rawi et al 2007 observed that serum LDL - cholesterol concentrations were significantly reduced in rats fed with oats instead of rats treated with atorvastatin ${ }^{(32)}$.

\section{CONCLUSION}

Oats can have positive results in eliminating LDL and should be included in food of individuals with atherosclerosis. More investigation is needed to know which components in oats contribute to these effects.

\section{REFERENCES}

1. Allouche Y, Beltran G, Gaforio JJ, Uceda M, Mesa MD. Antioxidant and anti atherogenic activities of pentacyclic triterpenic diols and acids. Food and Chemical Toxicology 2010; 48:2885-2890.

2. Ferdowsian HR, Barnard ND. Effect of plant- based diets on plasma lipids. Am.J.Cardiol 2009; 104:947-956.

3. Wick G, Romen M, Amberger A, Metzeler B \& Mayr M: Atherosclerosis, autoimmunity and vascular associated lymphoid tissue. FASEB J1997, 11(13):1199-207.

4. Tedgui A, Mallat Z. Cytokines in atherosclerosis: pathogenic and regulatory pathways. Physiol Rev. 2006; 86:515-581.

5. Rafieian-Kopaei M, Setorki M, Doudi M, Baradaran A, Nasri H. Atherosclerosis: process, indicators, risk factors and new hopes. Int J Prevent Med. 2014; 5: 927-946.

6. Drake, Richard L.; Vogl, Wayne; Mitchell, Adam W. M. Gray's anatomy for students. 2005 Philadelphia, Pennsylvania: Elsevier. pp. 989-995.

7. Prabha S.P, Ansil P.N, Nitha A, Wills P.J, Latha M.S: Anti-atherogenic activity of methanolic extract of Gardenia Gummifera Linn.F. On high fat diet induced atherosclerosis in rats. Int J Pharm Pharm Sci, 2013; 5, (2): 388-393.

8. Whitehead A, Beck EJ, Tosh S, Wolever TM. "Cholesterollowering effects of oat $\beta$-glucan: a meta-analysis of randomized controlled trials". Am J Clin Nutr. 2014; 100 (6): 1413-21.

9. Kurtz ES, Wallo W: Colloidal oatmeal: history, chemistry and clinical properties. J Drugs Dermatol. 2007; 6 (2):167170 .

10. Vader LW, Stepniak DT, Bunnik EM, et al. Characterization of cereal toxicity for celiac disease patients based on protein homology in grains. Gastroenterology. 2003; 125 (4):11051113.

11. Nazare JA, Normand S, Oste Triantafyllou A, Brac de la Perrière A, Desage M, Laville M. Modulation of the post- 
prandial phase by beta-glucan in overweight subjects: effects on glucose and insulin kinetics. Mol Nutr Food Res. 2009; 53 (3):361-9.

12. Sturtzel B, Dietrich A, Wagner KH, Gisinger C, Elmadfa I. The status of vitamins B6, B12, folate, and of homocysteine in geriatric home residents receiving laxatives or dietary fiber. J Nutr Health Aging. 2010; 14 (3):219-23.

13. Nie L, Wise ML, Peterson DM, Meydani M. Avenanthramide, a polyphenol from oats, inhibits vascular smooth muscle cell proliferation and enhances nitric oxide production. Atherosclerosis. 2006; 186(2):260-6.

14. Food and Drug Administration, HHS. Food labeling: health claims; soluble dietary fiber from certain foods and coronary heart disease. Final rule. Fed Regist.2003; 68(144):4420744209.

15. Storch KN, Taatjes DJ, Bouffard NA, Locknar S, Bishop NM, Langevin HM. Alpha smooth muscle actin distribution in cytoplasm and nuclear invaginations of connective tissue fibroblasts. Histochem Cell Biol 2007; 127(5):523-530.

16. Libby P: Changing concepts of atherogenesis. J Intern Med. 2000; 247(3):349-58.

17. Takahashi K, Takeya M, Sakashita N: Multifunctional roles of macrophages in the development and progression of atherosclerosis in human and experimental animals. Medical Electron Microscopy; 2002; 35:179.

18. Jacobs L R: Effects of dietary fiber on mucosal growth and cell proliferation in the small intestine of the rat: a comparison of oat bran, pectin, and guar with total fiber deprivation. Am. J. Clin. Nutr. 1983, 37: 954960.

19. Martha Srinivas, Akula Annapurna \& Yellu Narsimha Reddy: Antiatheroscerotic effect of atorvastatin and clopidogrel alone and in combination in rats. Indian Journal of Experimental Biology .2008; 46:698-703.

20. Shinnick FL, Ink SL, Marlett JA. Dose response to a dietary oat bran fraction in cholesterol-fed rats. J Nutr 1990; 120:561-8.

21. Libby P. Atherosclerosis. In: Fauci AS, Braunwald E, Isselbacher KJ, et al., editors. Harrison's Principles of Internal Medicine. 14. New York: McGraw-Hill; 1998. pp. 1345-52.

22. Reynertson KA, Garay M, Nebus J, Chon S, Kaur S, Mahmood K, Kizoulis M, Southall MD. Anti-inflammatory activities of colloidal oatmeal (Avena sativa) contribute to the effectiveness of oats in treatment of itch associated with dry, irritated skin. J Drugs Dermatol. 2015; 14:43-8.
23. Yan-Jun Jia, Jun Liu, Yuan-Lin Guo, Rui-Xia Xu, Jiang Sun, and Jian-Jun Li: Dyslipidemia in rat fed with high-fat diet is not associated with PCSK9-LDL-receptor pathway but ageing. J Geriatr Cardiol. 2013; 10(4): 361-368.

24. M. Brochu, E.T. Poehlman, P.A. AdesObesity, body fat distribution, and coronary artery disease .J. Cardiopulm. Rehabil., 20 (2000), pp. 96-108.

25. Irena Vukovic, Nebojsa Arsenijevic, Vesna Lackovic, and Vera Todorovic The origin and differentiation potential of smooth muscle cells in coronary atherosclerosis. Exp Clin Cardiol. 2006 summer; 11(2): 123-128.

26. R. Ojeda and P. A. Aljama: Chronic microinflammation and endothelial damage in uremia. Nefrología 2008; 28 (6) 583 586.

27. Liu L, Zubik L, Collins FW, Marko M, Meydani M. The antiatherogenic potential of oat phenolic compounds. Atherosclerosis. 2004; 175 (1):39-49.

28. Queenan KM, Stewart ML, Smith KN, Thomas W, Fulcher RG, Slavin JL. Concentrated oat beta-glucan, a fermentable fiber, lowers serum cholesterol in hypercholesterolemic adults in a randomized controlled trial. Nutr J. 2007; 6: 6 . 17386092.

29. Kisoo Pahk, Chanmin Joung, Se-Mi Jung, Hwa Young Song, Ji Yong Park, Jung Woo Byun, Yun-Sang Lee, Jin Chul Paeng, Chunsook Kim, Sungeun Kim \& Won-Ki Kim: Visualization of Synthetic Vascular Smooth Muscle Cells in Atherosclerotic Carotid Rat Arteries by F-18 FDG PET. Scientific Report 2017; (7), Article number: 6989 DOI: 10.1038/s41598-017-07073-3.

30. Azuma K, Ichimura K, Mita T, Nakayama S, Jin WL, Hirose T, Fujitani Y, Sumiyoshi K, Shimada K, Daida H, Sakai T, Mitsumata M, Kawamori R, Watada H. Presence of alphasmooth muscle actin-positive endothelial cells in the luminal surface of adult aorta. Biochem Biophys Res Commun. 2009, 13; 380 (3):620-6.

31. Andersson KE, Svedberg KA, Lindholm MW, Oste R, Hellstrand P. Oats (Avena sativa) reduce atherogenesis in LDL-receptor-deficient mice. Atherosclerosis. 2010; 212 (1):93-9.

32. Maisaa M. AL-Rawi: Efficacy of oat bran (Avena sativa L.) in comparison with atorvastatin in treatment of hypercholesterolemia in albino rat liver. The Egyptian Journal of Hospital Medicine 2007; 29: 511- 521. 